This item was submitted to Loughborough's Research Repository by the author.

Items in Figshare are protected by copyright, with all rights reserved, unless otherwise indicated.

\title{
Maternal symptoms of depression are related to observations of controlling feeding practices in mothers of young children
}

PLEASE CITE THE PUBLISHED VERSION

http://dx.doi.org/10.1037/a0031110

PUBLISHER

(C) American Psychological Association

VERSION

AM (Accepted Manuscript)

LICENCE

CC BY-NC-ND 4.0

\section{REPOSITORY RECORD}

Haycraft, Emma, Claire V. Farrow, and Jacqueline Blissett. 2019. "Maternal Symptoms of Depression Are Related to Observations of Controlling Feeding Practices in Mothers of Young Children". figshare. https://hdl.handle.net/2134/11940. 
This item was submitted to Loughborough's Institutional Repository (https://dspace.lboro.ac.uk/) by the author and is made available under the following Creative Commons Licence conditions.

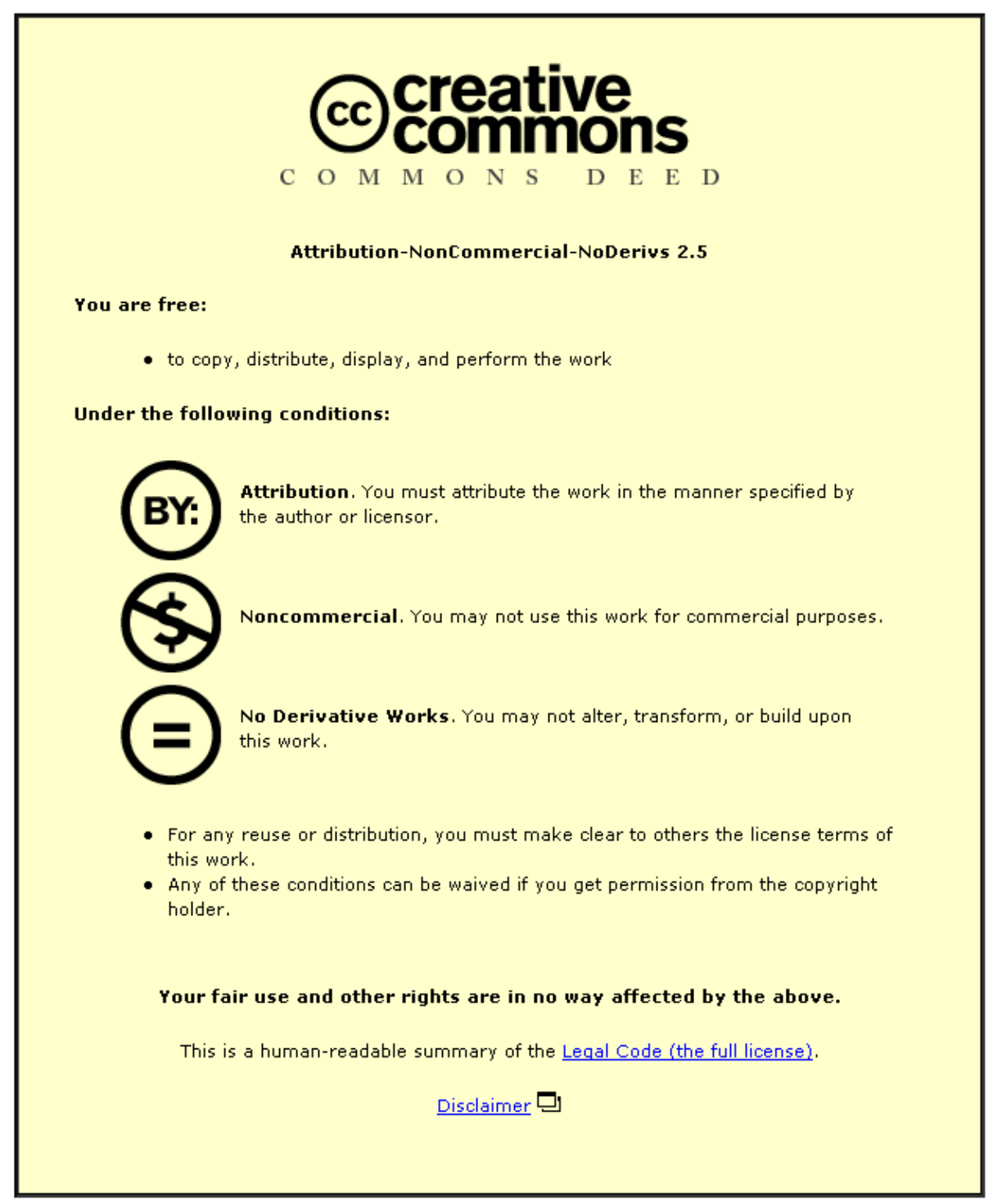

For the full text of this licence, please go to: http://creativecommons.org/licenses/by-nc-nd/2.5/ 
Maternal symptoms of depression are related to observations of controlling feeding practices in mothers of young children

Emma Haycraft, $\mathrm{PhD}^{1}$ *, Claire Farrow, $\mathrm{PhD}^{1}$, \& Jackie Blissett, $\mathrm{PhD}^{2}$

${ }^{1}$ Loughborough University Centre for Research into Eating Disorders, School of Sport, Exercise and Health Sciences, Loughborough University, UK.

${ }^{2}$ School of Psychology, University of Birmingham, UK

*Address correspondence to: Dr Emma Haycraft, Loughborough University Centre for Research into Eating Disorders, School of Sport, Exercise and Health Sciences, Loughborough University, Leicestershire LE11 3TU, UK. Email: E.Haycraft@lboro.ac.uk Not for publication: Tel. +44(0)1509 228160; Fax. +44(0)15093340. 


\begin{abstract}
Maternal depression can impair parenting practices and has been linked with less sensitive feeding interactions with children, but existing research is based on self-reports of feeding practices. This study aimed to examine relationships between maternal self-reported symptoms of depression with observations of mothers' child feeding practices during a mealtime. Fifty-eight mothers of 3-4 year old children were video recorded eating a standardised lunch. The recording was then coded for instances of maternal controlling feeding practices and maternal vocalisations using the Family Mealtime Coding System. Mothers also provided information on current symptoms of depression and anxiety. Mothers who reported greater symptoms of depression were observed to use more verbal and physical pressure for their child to eat and to offer more incentives or conditions in exchange for their child eating. Mothers also used more vocalisations with their child about food during the observed mealtime when they had greater symptoms of depression. There was no link between symptoms of depression and observations of maternal use of restriction. Symptoms of depression are linked with observations of mothers implementing a more controlling, less sensitive feeding style with their child. Health professionals working with families where mothers have symptoms of depression may benefit from receiving training about the possible impact of maternal depression on child feeding practices, while mothers with symptoms of depression may benefit from guidance regarding its potential impact on their child feeding interactions.
\end{abstract}

Keywords: Pressure to eat; Incentives; Mealtime environment; Intrusive parenting; Feeding interactions. 


\section{Maternal symptoms of depression are related to observations of controlling feeding practices in mothers of young children}

The adverse effects of maternal depression on parenting practices have been well documented (e.g., Downey \& Coyne, 1990; Lovejoy, Graczyk, O’Hare \& Neuman, 2000). Maternal depression has been associated with disruptions in childrearing practices (e.g., Cummings \& Davies, 1994), with hostility, coercion, withdrawal, and lower parental selfefficacy (e.g., Cox, Puckering, Pound \& Mills, 1987; Cummings \& Davies, 1994; Stein et al., 2001), as well as with adverse child development or adjustment, such as antisocial behaviour (Downey \& Coyne, 1990).

The presence of symptoms of depression can impair parents' sensitivity and responsiveness to their children, leading to either authoritarian or disengaged parenting behaviours (e.g., Leinonen, Solantus \& Punamäki, 2003; Pelaez, Field, Pickens \& Hart, 2008), or to parents being less likely to use explanations or reasoning with their children (Cox et al., 1987). Symptoms of depression may alter interactions between parent and child (Cummings \& Davies, 1994) and one area in which parent-child interactions are particularly important in the early years is child feeding. Symptoms of depression have been associated with early termination of breastfeeding (Cooper, Murray \& Stein, 1993), with difficult feeding interactions (Blissett, Meyer \& Haycraft, 2007) and increased duration of child food refusal (Coulthard \& Harris, 2003), and also with the use of less sensitive child feeding practices (e.g., Francis, Hofer \& Birch, 2001; Haycraft \& Blissett, 2008a; Hurley, Black, Papas \& Canfield, 2008; Mitchell, Brennan, Hayes \& Miles, 2009). Indeed, Francis et al. (2001), Haycraft and Blissett (2008a), and Hurley et al. (2008) have all found maternal symptoms of depression to relate to greater use of forceful or pressuring child feeding practices. The use of such feeding practices, often termed 'controlling' feeding practices, may reduce the extent to which children respond to their internal signals of hunger and satiety 
(Birch \& Fisher, 1998). Controlling practices include pressuring a child to eat or restricting intake of particular foods. These feeding practices can also alter the emotional climate of mealtimes (Hughes et al., 2011) and can impact on children's developing relationships with food, with more controlling practices being linked to more emotional (Blissett, Haycraft \& Farrow, 2010) and avoidant (Webber, Cooke, Hill \& Wardle, 2010) eating behaviours in children. Thus, the use of controlling feeding practices can have unintended and undesirable consequences for children's healthy development.

However, much of the previous literature which has linked depression to the use of these detrimental feeding practices is based on self-reports of feeding practices, so it is not known whether mothers who report greater symptoms of depression actually do engage in more controlling feeding practices with their children, or whether these findings are a function of a bias in reporting. To address this, the current study aimed to examine relationships between self-reported maternal symptoms of depression with observations of feeding practices with their child in a laboratory setting. Young children, aged 3-4, were chosen for this study as, at this age, parents are still likely to be primarily responsible for feeding their children. It was hypothesised that greater symptoms of depression would be associated with observations of more controlling feeding practices. Given the frequent comorbidity of depression and anxiety (e.g., Coulthard \& Harris, 2003; Sartorius, Ustun, Lecrubier \& Wittchen, 1996), and the links between maternal anxiety and feeding practices (e.g., Blissett et al., 2007; Coulthard \& Harris, 2003), anxiety will be controlled for in the analyses, thereby allowing for the unique contribution of symptoms of depression to mothers' child feeding practices to be considered.

\section{METHOD}

\section{Participants}


Fifty-eight mothers with a child aged 3-4 years participated in a study of children's eating behaviours; other data from which have been published elsewhere (Farrow, Blissett \& Haycraft, 2011). Participants were recruited via university newsletters distributed to alumni and the local community. Mothers' mean age was 34 years (SD 5.48) and their mean BMI score was 24.8 (SD 5.10), which is just below the cut-off for overweight (BMI > 25). Mothers reported an average of 4 years of education after the age of 16 (SD 2.91) and most (91\%) reported their nationality as British. The mean child age was 3.8 years (SD 0.58) and

child gender was fairly evenly split (boys $n=30,52 \%$; girls $n=28,48 \%$ ). The mean child BMI z-score, standardised for age and gender using the Child Growth Foundation (1996) reference curves, was 0.09 (SD 0.94, range -2.15 to 2.92 ), indicating that children were generally of healthy weight.

\section{Measures and procedure}

Following ethical approval and informed consent, mothers brought their child in for lunch at Loughborough University's children's eating behaviour laboratory. Children and their mothers initially played with toys and familiarised themselves with their surroundings for 5-10 minutes before they received a standardised, palatable but healthy lunch. The content of the lunch was based on previous studies which have used child-friendly meals (e.g., Cooke, Carnell \& Wardle, 2006) and cookies were included alongside the savoury foods to potentially elicit parental restriction. Prior to coming in to take part in the study, mothers had listed any foods that their child did not like or would not eat and none of these foods were included in the meal. Children were given a white bread roll, half a slice of cheese, half a slice of chicken, four cheese crackers, five carrot sticks, two chocolate chip cookies, three pieces of sliced apple and a glass of water. Mothers were given two bread rolls, one slice of chicken and one slice of cheese, and vegetarians received additional cheese 
instead of chicken (see Farrow et al., 2011 for further details about the meals). Children were asked to eat as much as they wanted to and could request additional food if they desired, although no children did so. Mothers and children were told to eat the meal as they usually would do at home and the researcher left the room while they ate.

The mealtime was video recorded and subsequently coded in real time using the Family Mealtime Coding System (FMCS; Haycraft \& Blissett, 2008b). Five feeding practice subscales were coded: verbal pressure to eat (e.g., "have another mouthful"); physical pressure to eat (e.g., pushing the plate of food towards the child); verbal restriction of foods (e.g., "don't eat that cookie now”); physical restriction of food (e.g., removal of a food from the child's plate); and use of incentives/conditions (e.g., "if you eat one more mouthful, you can play with the toys" or "if you don't try this, you won't go swimming later"). The frequency that each of these feeding practices was observed was recorded and a total score for each subscale was created for each parent. In addition to coding observations of controlling feeding practices, positive (e.g., “this tastes nice!”) and negative (e.g., "I don't like that either") vocalisations about food made by the mother to her child during the mealtime were coded and the frequency that each occurred was logged to create total positive and negative vocalisation scores. These constructs were assessed because some parents with symptoms of depression have been found to use more negative vocalisations when communicating with their children (e.g., Field, 2010) and also because of evidence that parents with disorders that predispose them to use controlling feeding practices have a tendency to display higher levels of emotional expression during mealtimes (e.g., Barnes et al., 2007; Stein, Woolley, Cooper \& Fairburn, 1994). While the use of a few comments, either positive or negative, about food is typical a parent-child mealtime interactions, a greater use of either type of comment may be intrusive and therefore maladaptive. Finally, we coded children's acceptance of food by counting the number of mouthfuls that they were 
observed to consume during the mealtime. The FMCS has previously shown good inter-rater reliability (e.g., Haycraft \& Blissett, 2008b). In the current sample, 26\% $(n=15)$ of the videos were coded by a second rater, with the intra-class correlation coefficients for the seven FMCS variables ranging from $.44(p=.044)$ to $.94(p<.001)$, indicating fair to strong inter-rater agreement.

After the mealtime, each mother provided background and demographic information about herself and her child and completed the Hospital Anxiety and Depression Scale (HADS; Zigmond \& Snaith, 1983) while her child played with toys. The HADS is a 14-item questionnaire which measures symptoms of anxiety ( 7 items) and depression ( 7 items). Each question has four response options. Possible scores range from 0 to 21 for each subscale. Scores from 0-7 indicate low levels of anxiety/depression, 8-10 suggests mild symptoms, a score from 11-14 indicates moderate levels, and scores of 15-21 suggest severe symptoms of anxiety/depression (Zigmond \& Snaith, 1983). ${ }^{1}$ The HADS is widely used and displays adequate validity and reliability (e.g., Bjelland, Dahl, Haug \& Neckelmann, 2002; Herrmann, 1997; Zigmond \& Snaith, 1983). Cronbach's alpha levels for the HADS in this sample were acceptable (depression $\alpha=.75$; anxiety $\alpha=.70)$.

Following this, children and their parents were weighed and measured, without shoes and wearing light clothes, in order that parent BMI and child BMI z-scores could be calculated.

\section{Data analysis}

Preliminary Pearson's correlations were run to test for relationships between child age, child BMI z-scores, maternal education and maternal BMI with the five observed feeding practices and maternal mealtime vocalisations. The only significant relationship was

\footnotetext{
${ }^{1}$ Coders of the mealtime observations were not aware of mothers' HADS scores, meaning that mealtimes were coded blind to participants' level of depressive symptoms.
} 
between child age with verbal pressure to eat $(r=-.290, p=.027)$, so child age was controlled for in further analyses. There was some variability in the duration of mealtimes (see Table 1) and so this was also controlled for in the analyses, to take account of the different amounts of time during which controlling feeding practices and comments about food might be observed. In addition, while maternal symptoms of depression were not significantly correlated with the number of mouthfuls of food that their child was observed to consume during the mealtime $(r=.126, p>.05)$, in order to account for variability in children's eating behaviour which has the potential to influence parents' feeding practices, we also controlled for the number of mouthfuls children consumed in our analyses. Finally, one-tailed Pearson's correlations identified that, as expected, depression was significantly correlated with anxiety $(r=.530, p<.001)$ and so anxiety was also controlled for in the analyses, as planned.

\section{RESULTS}

Descriptive statistics for this sample are presented in Table 1.

\section{---TABLE 1---}

The mean duration of the mealtimes was 22 minutes and children consumed an average of 49 mouthfuls of food. The mean HADS depression score indicates mild levels of depression in this sample. Further examination of the sample in relation to cut-off points suggested by the authors (Zigmond \& Snaith, 1983) suggests that $48 \%$ are classified as having low levels of symptoms of depression, $9 \%$ have mild levels and $41 \%$ have moderate levels of depression symptoms. One person was classified as having severe symptoms of depression. These levels are similar to those in other research with mothers of young children (e.g., Hall, 1990; Mulvaney \& Kendrick, 2005). 
The observed feeding practices data are broadly in line with other samples which have used the FMCS (e.g., Blissett \& Haycraft, 2011; Haycraft \& Blissett, 2008b). As with other studies, pressure (verbal and physical) was used significantly more than restriction (verbal and physical) during the meal (verbal $t=6.39, p<.0001$; physical $t=5.09, p<.0001$ ), as the frequency of restriction is often relatively low during mealtimes (Haycraft \& Blissett, 2008b; Orrell-Valente et al., 2007). The data in Table 1 also suggest that mothers generally made more positive than negative vocalisations about food during the mealtime, although this difference was not statistically significant $(t=-0.67, p>.05)$.

In order to test the hypothesis that greater symptoms of depression would be associated with observations of more controlling feeding practices, a series of one-tailed partial correlations was run, controlling for maternal anxiety, child age, the number of mouthfuls of food accepted, and the mealtime duration (see Table 2). Furthermore, additional correlations were run between the FMCS subscales in order to identify any correlations between maternal feeding practices and vocalisations assessed in this study (see Table 2).

\section{---TABLE 2---}

Higher levels of depressive symptoms were significantly related to increased use of verbal and physical pressure to eat but there were no significant correlations found between symptoms of depression and verbal or physical restriction. Higher levels of depressive symptoms were also related to greater use of incentives or conditions to eat and to an increased number of both positive and negative vocalisations about food made by the mother during the observed mealtime.

There were a number of significant correlations between subscales of the FMCS. Specifically, mothers observed to use greater verbal pressure also used more physical pressure, verbal restriction, incentives and positive vocalisations. Mothers who used more 
physical pressure also used more verbal restriction, incentives/conditions and positive vocalisations. Mothers who used more verbal restriction also used more physical restriction and more incentives. Finally, mothers who used more incentives/conditions also used more positive vocalisations. Maternal negative vocalisations were unrelated to any other observed maternal feeding practices.

\section{DISCUSSION}

This study examined associations between observations of maternal use of controlling feeding practices with self-reported maternal symptoms of depression in a sample of mothers of young children. Higher levels of depressive symptoms were related to greater use of verbal and physical pressure for children to eat, increased use of incentives, and a higher incidence of maternal vocalisations about food during the observed meal. Symptoms of depression were not significantly linked to observations of restriction of food.

These findings support and extend previous literature which has found depression to be related to reports of controlling feeding practices (Francis et al., 2001; Haycraft \& Blissett, 2008a; Hurley et al., 2008; Mitchell et al., 2009). Specifically, symptoms of depression were linked to increased observations of pressure to eat and use of incentives; practices consistent with a more authoritarian parenting style, which is often exhibited by mothers with symptoms of depression (e.g., Leinonen et al., 2003; Pelaez et al., 2008). Furthermore, maternal symptoms of depression were related to mothers making more positive and negative vocalisations about food to children during the meal. It seems logical that mothers who are engaging in higher levels of pressure for their children to eat and using more incentives may also engage in more discussion about foods. Although maternal comments are coded as positive or negative, they are food-specific, for example, “this tastes nice" or "I don't like that". Therefore, a mother may make many comments regarding how pleasant the food is, 
but this is not necessarily indicative of positive mother-child interactions. When considered together, the findings suggest that mothers in this sample with higher levels of depressive symptoms were engaging in more intrusive, less sensitive feeding practices, as are often seen in mothers with symptoms of depression (Field, Hernandez-Reif \& Diego, 2006), and highlight that mealtimes may not be typified by withdrawal from interactions in mothers with symptoms of depression. It is possible that these mothers with higher levels of depression may be more 'task' focussed or try harder to engage their children in eating and so pay greater attention to the food aspects of the meal rather than general mealtime interaction with their child, as indicated by these mothers exhibiting more controlling practices and a greater number of positive and negative comments about food. This notion aligns with research which has found maternal symptoms of depression or postnatal depression to be related to disrupted interactions with their children (e.g., Cummings \& Davies, 1994; Field, 2010; Lovejoy et al., 2000), and for these mothers to be less sensitive to their children's needs, to use more controlling and intrusive interaction styles, and to be less playful (see Field, 2010, for a review). Further research is warranted, to help elucidate whether the feeding practices and vocalisations relate to more challenging feeding behaviours exhibited by the child, as is sometimes seen in children with feeding disorders, where food refusal and feeding problems have been shown to be reinforced by caregiver attention (e.g., Babbitt et al., 1994; Kerwin, 2003; Galensky, Miltenberger, Stricker, Garlinghouse, \& Koegel, 2001), and in families where parents are experiencing more dysfunctional romantic relationships (e.g., Haycraft \& Blissett, 2010).

In interpreting these findings, it is noteworthy that many of the observed feeding practices were significantly and positively correlated with each other, suggesting the cooccurrence of controlling feeding practices, as has been found in other research (e.g., Gregory, Paxton \& Brozovic, 2010). These inter-relationships may suggest that some 
mothers adopt a generally more controlling feeding style, rather than distinct feeding behaviours (e.g., a mother may be controlling in her general attitude towards feeding rather than specifically pressuring), and that depression may be related to a more generally controlling style of feeding rather than specific feeding practices. Future research with larger sample sizes may benefit from examining feeding styles as well as practices.

These findings make an important step in advancing the existent self-report literature. The research evidence is mixed regarding whether parents' self-reported feeding practices accurately reflect their observed behaviours (e.g., Haycraft \& Blissett, 2008b; Whelan \& Cooper, 2000) and so the observation of mothers' child feeding practices is a clear strength of this study. However, the sample size was relatively modest and only one mealtime within a laboratory setting was observed per family. Furthermore, differing amounts of variance were observed in the FMCS subscales, with greater variability seen in the subscales which significantly correlated with depression, which may have contributed to the pattern of significant (and insignificant) relationships seen here. There was also variability in the strength of the intra-class correlations for the FMCS, which ranged from fair to strong agreement between the two raters, suggesting that some practices may have been more reliably coded than others. Future research should replicate this study in larger samples where the larger sample size may result in greater variability of scores across all subscales. The HADS was completed after the mealtime and it is noted that the preceding mealtime interaction has the potential to influence mothers' responses on this measure. The FMCS only considers controlling feeding practices and it would be interesting for further work to explore whether symptoms of depression in mothers are related to the use of other, noncontrolling feeding practices. Such work would enable researchers to make potential recommendations about the types of feeding practices that mothers with symptoms of depression should be advised to use and will therefore build on this study's findings which 
have highlighted which controlling feeding practices mothers with depressed mood should be advised to avoid. Further work with clinical samples and within the home may usefully expand on the study's findings, as might research which considers the emotional quality of the parent-child relationship in addition to food-specific interactions.

In conclusion, this study has shown the presence of symptoms of depression in mothers of young children to be related to observations of maternal use of more controlling and intrusive feeding practices. Although requiring replication, these preliminary findings may be useful for clinicians and health professionals working with families where mothers have symptoms of depression, who may benefit from receiving training about the possible effects of maternal depression on a mother's child feeding practices. Additionally, guidance regarding the use of appropriate and responsive feeding practices, such as reducing pressure to eat and the use of incentives for eating, but using more role modelling and providing a variety of healthy foods (Palfreyman, Haycraft \& Meyer, in press; Scaglioni, Salvioni \& Galimberti, 2008), may also be useful for mothers with symptoms of depression.

\section{Acknowledgements}

We thank Laura Houldcroft, Faye Powell and Hannah White for their assistance with data collection. This research was not externally funded and the authors have no competing interests to report. 


\section{References}

Babbitt, R.L., Hoch, T.A., Coe, D.A., Cataldo, M.F., Kelly, K.J., Stackhouse, C., \& Perman, J.A. (1994). Behavioral-assessment and treatment of pediatric feeding disorders. Journal of Developmental and Behavioral Pediatrics, 15(4), 278-291.

Barnes, J., Ram, B., Leach, P., Altmann, L., Sylva, K., Malmberg, L., Stein, A., \& FCCC Team. (2007). Factors associated with negative emotional expression: A study of mothers of young infants. Journal of Reproductive and Infant Psychology, 25, 122138.

Birch, L.L. \& Fisher, J.O. (1998). Development of eating behaviors among children and adolescents. Pediatrics, 101, 539-549

Bjelland, I., Daahl, A.A., Haug, T.T., \& Neckelmann, D. (2002). The validity of the Hospital Anxiety and Depression Scale: An updated literature review. Journal of Psychosomatic Research, 52, 69-77.

Blissett, J. \& Haycraft, E. (2011). Parental eating disorder symptoms and observations of mealtime interactions with children. Journal of Psychosomatic Research, 70, 368-371.

Blissett, J., Haycraft, E. \& Farrow, C. (2010). Inducing preschool children's emotional eating: Relations with parental feeding practices. American Journal of Clinical Nutrition, 92, 359-365.

Blissett, J., Meyer, C. \& Haycraft, E. (2007). Maternal mental health and child feeding problems in a non-clinical group. Eating Behaviors, 8, 311-318

Child Growth Foundation. (1996). Cross Sectional Stature and Weight Reference Curves for the UK. London, United Kingdom: Child Growth Foundation.

Cooke, L., Carnell, S., \& Wardle, J. (2006). Food neophobia and mealtime food consumption in 4-5 year old children. International Journal of Behavioral Nutrition and Physical Activity, 6(3), 14. 
Cooper, P.J., Murray, L., \& Stein, A. (1993). Psychosocial factors associated with the early termination of breast-feeding. Journal of Psychosomatic Research, 37, 171-176.

Coulthard, H. \& Harris, G. (2003). Early food refusal: The role of maternal mood. Journal of Reproductive and Infant Psychology, 21, 335-345

Cox, A. D., Puckering, C., Pound, A., \& Mills, M. (1987). The impact of maternal depression in young children. Journal of Child Psychology and Psychiatry and Allied Disciplines, 28, 917-928.

Cummings, E. M. \& Davies, P. T. (1994). Maternal depression and child development. Journal of Child Psychology and Psychiatry, 35, 73-112.

Downey, G., \& Coyne, J. C. (1990). Children of depressed parents: An integrative review. Psychological Bulletin, 108, 50-76.

Farrow, C., Blissett, J. \& Haycraft, E. (2011). Does child weight influence how mothers report their feeding practices? International Journal of Pediatric Obesity, 6, 306-313.

Field, T. (2010). Postpartum depression effects on early interactions, parenting, and safety practices: A review. Infant Behavior \& Development, 33, 1-6.

Field, T., Hernandez-Reif, M., \& Diego, M. (2006). Intrusive and withdrawn depressed mothers and their infants. Developmental Review, 26, 15-30.

Francis, L.A., Hofer, S.M., \& Birch, L.L. (2001). Predictors of maternal child-feeding style: maternal and child characteristics. Appetite, 37, 231-243.

Galensky, T. L., Miltenberg, R.G., Stricker, J. M., \& Garlinghouse, M. A. (2001). Functional assessment and treatment of mealtime behavior problems. Journal of Positive Behavior Intervention, 3, 211-224.

Gregory, J.E., Paxton, S.J., \& Brozovic, A.M. (2010). Pressure to eat and restriction are associated with child eating behaviours and maternal concern about child weight, but not child body mass index, in 2- to 4-year-old children. Appetite, 54, 550-6. 
Hall, L.A. (1990). Prevalence and correlates of depressive symptoms in mothers of young children. Public Health Nursing, 7, 71-79.

Haycraft, E. \& Blissett, J. (2008a). Controlling feeding practices and psychopathology in a non-clinical sample of mothers and fathers. Eating Behaviors, 9, 484-492.

Haycraft, E. \& Blissett, J. (2008b). Maternal and paternal controlling feeding practices: Reliability and relationships with BMI. Obesity, 16, 1552-1558.

Haycraft, E. \& Blissett, J. (2010). The role of parents' romantic relationship warmth and hostility in child feeding practices and children's eating behaviours. Maternal and Child Nutrition, 6, 266-274.

Hermann, C. (1997). International experiences with the Hospital Anxiety and Depression Scale: A review of validation data and clinical results. Journal of Psychosomatic Research, 42, 17-41.

Hughes, S.O., Power, T.G., Papaioannou, M.A., Cross, M.B., Nicklas, T.A., Hall, S.K., \& Shewchuk, R.M. (2011). Emotional climate, feeding practices, and feeding styles: an observational analysis of the dinner meal in Head Start families. International Journal of Behavioral Nutrition and Physical Activity, 10, 8:60.

Hurley, K.M., Black, M.M., Papas, M.A., \& Canfield, L.E. (2008). Maternal symptoms of stress, depression, and anxiety are related to nonresponsive feeding styles in a statewide sample of WIC participants. Journal of Nutrition, 138, 799-805.

Kerwin, M.E. (2003). Pediatric feeding problems: A behavior analytic approach to assessment and treatment. The Behavior Analyst Today, 4(2), 162-176.

Leinonen, J. A., Solantaus, T. S., \& Punamäki, R. L. (2003). Parental mental health and children's adjustment: The quality of marital interaction and parenting as mediating factors. Journal of Child Psychology and Psychiatry, 44, 227-241. 
Lovejoy, C.M., Graczyk, P.A., O’Hare, E., \& Neuman, G. (2000). Maternal depression and parenting behavior: A meta-analytic review. Clinical Psychology Review, 20, 561-592.

Mitchell, S., Brennan, L., Hayes, L., \& Miles, C.L. (2009). Maternal psychosocial predictors of controlling parental feeding styles and practices. Appetite, 53, 384-389.

Mulvaney, C. \& Kendrick, D. (2005). Depressive symptoms in mothers of pre-school children--effects of deprivation, social support, stress and neighbourhood social capital. Social Psychiatry and Psychiatric Epidemiology, 40, 202-8

Orrell-Valente, J.K., Hill, L.G., Brechwald, W.A., Dodge, K.A., Pettit, G.S., \& Bates, J.E. (2007). "Just three more bites": An observational analysis of parents' socialization of children's eating at mealtime. Appetite, 48, 37-45.

Palfreyman, Z., Haycraft, E., \& Meyer, C. (in press). Development of the Parental Modelling of Eating Behaviours Scale (PARM): Links with food intake among children and their mothers. Maternal and Child Nutrition. DOI: 10.1111/j.1740-8709.2012.00438.x

Pelaez, M., Field, T., Pickens, J.N., \& Hart, S. (2008). Disengaged and authoritarian parenting behavior of depressed mothers with their toddlers. Infant Behavior \& Development, 31, 145-148

Sartorius, N., Ustun, T.B., Lecrubier, Y., \& Wittchen, H.U. (1996). Depression comorbid with anxiety: Results from the WHO study on Psychological Disorders in Primary Health Care. British Journal of Psychiatry, 168, 38-43.

Scaglioni, S., Salvioni M., \& Galimberti, C. (2008). Influence of parental attitudes in the development of children eating behaviour. British Journal of Nutrition, 99, S22-S25.

Stein, A., Woolley, H., Cooper, S. D., \& Fairburn, C. G. (1994). An observational study of mothers with eating disorders and their infants. Journal of Child Psychology and Psychiatry, 35, 733-748. 
Stein, A., Woolley, H., Murray, L., Cooper, P. J., Cooper, S., Noble, F. et al. (2001). Influence of psychiatric disorder on the controlling behaviour of mothers with oneyear-old infants: A study of women with maternal eating disorder, postnatal depression and a healthy comparison group. British Journal of Psychiatry, 179, 157-162.

Webber, L., Cooke, L., Hill, C., \& Wardle, J. (2010). Associations between children's appetitive traits and maternal feeding practices. Journal of the American Dietetic Association, 110, 1718-1722.

Whelan, E. \& Cooper, P.J. (2000). The association between childhood feeding problems and maternal eating disorder: a community study. Psychological Medicine, 30, 69-77.

Zigmond, A.S. \& Snaith, R.P. (1983). The Hospital Anxiety and Depression Scale. Acta Psychiatrica Scandinavica, 67, 361-370. 
Table 1

Descriptive statistics for mealtime duration, mouthfuls consumed and the measures obtained $(N=58)$

\begin{tabular}{|c|c|c|c|}
\hline & Mean (SD) & Minimum & Maximum \\
\hline Mealtime duration (minutes) & $21.68(6.04)$ & 11.97 & 38.66 \\
\hline Number of mouthfuls eaten by child & $49(18.41)$ & 20 & 104 \\
\hline \multicolumn{4}{|c|}{ Hospital Anxiety and Depression Scale (HADS) } \\
\hline Depression & $7.76(5.28)$ & 0 & 15 \\
\hline Anxiety & $7.41(2.77)$ & 2 & 12 \\
\hline \multicolumn{4}{|l|}{ Family Mealtime Coding Scheme (FMCS) } \\
\hline Verbal pressure & $8.03(8.98)$ & 0 & 45 \\
\hline Physical pressure & $5.10(7.18)$ & 0 & 34 \\
\hline Verbal restriction & $1.14(1.77)$ & 0 & 8 \\
\hline Physical restriction & $0.45(0.86)$ & 0 & 3 \\
\hline Incentives/conditions & $1.31(2.26)$ & 0 & 11 \\
\hline Positive maternal vocalisations about & $3.14(2.78)$ & 0 & 12 \\
\hline \multicolumn{4}{|l|}{ food } \\
\hline Negative maternal vocalisations about & $0.22(0.60)$ & 0 & 3 \\
\hline food & & & \\
\hline
\end{tabular}


Table 2

One-tailed partial correlations between depression (HADS) with observed controlling feeding practices and maternal mealtime vocalisations about food (FMCS), and between FMCS subscales, controlling for maternal anxiety (HADS), child age and mouthfuls eaten, and mealtime duration.

\begin{tabular}{|c|c|c|c|c|c|c|c|}
\hline & Depression & 1 & 2 & 3 & 4 & 5 & 6 \\
\hline 1. Verbal pressure & $.458 * * *$ & - & - & - & - & - & - \\
\hline 2. Physical pressure & $.381 * *$ & $.827 * * *$ & - & - & - & - & - \\
\hline 3. Verbal restriction & .139 & $.442 * * *$ & $.291 *$ & - & - & - & - \\
\hline 4. Physical restriction & .105 & .204 & .190 & $.604 * * *$ & - & - & - \\
\hline $\begin{array}{l}\text { 5. Incentives / } \\
\text { conditions }\end{array}$ & $.315^{*}$ & $.706 * * *$ & $.782 * * *$ & $.242 *$ & .230 & - & - \\
\hline $\begin{array}{l}\text { 6. Positive maternal } \\
\text { vocalisations about }\end{array}$ & $.419 * * *$ & $.365 * *$ & $.304 *$ & .158 & -.006 & $.369 * *$ & - \\
\hline food & & & & & & & \\
\hline 7. Negative maternal & & & & & & & \\
\hline $\begin{array}{l}\text { vocalisations about } \\
\text { food }\end{array}$ & $.243 *$ & .132 & .127 & .098 & .099 & .105 & .143 \\
\hline
\end{tabular}

$* \mathrm{p} \leq .05 ; * * \mathrm{p} \leq .01, * * * \mathrm{p} \leq .001$ 